\title{
Analisis Clustering K-Medoids Berdasarkan Indikator Kemiskinan di Jawa Timur Tahun 2020
}

\author{
Febiyanti Alfiah $^{1)}$, Almadayani1 ${ }^{1)}$, Danial Al Farizi ${ }^{1)}$, Edy Widodo ${ }^{1)}$ \\ ${ }^{1)}$ Program Studi Statistika, Fakultas Matematika dan Ilmu Pengetahuan Alam, Universitas \\ Islam Indonesia, Yogyakarta, Indonesia \\ febiyantialfiah1010@gmail.com; almadayani045@gmail.com; edywidodo@uii.ac.id
}

\begin{abstract}
ABSTRAK
Keberadaan pandemi COVID-19 di Indonesia, mengakibatkan kemiskinan di Indonesia semakin tinggi terutama di Jawa Timur yang menjadi satu diantara provinsi lain dengan kasus COVID-19 tinggi di Indonesia. Tujuan penelitian ini yaitu mengetahui pengelompokan kabupaten/kota di Jawa Timur yang mempunyai kesamaan karakteristik berdasarkan indikator kemiskinan tahun 2020. Penelitian ini menggunakan data yang didapatkan dari Badan Pusat Statistik. Metode yang digunakan ialah metode k-medoids clustering yang merupakan metode partisi clustering guna pengelompokan $n$ objek ke dalam $k$ cluster. Berdasarkan hasil penelitian, diperoleh pengelompokan karakteristik masing-masing cluster yang dibentuk berdasarkan nilai indikator kemiskinan di Jawa Timur tahun 2020 sebanyak 2 cluster. Dimana 30 kabupaten/kota pada cluster 1 dan dan 8 kabupaten/kota pada cluster 2. Cluster 1 memiliki karakteristik Persentase Rumah Tangga yang Mempunyai Sanitasi Layak, Angka Harapan Hidup, dan Persentase Angka Melek Huruf Umur 15-55 Th tinggi. Sedangkan cluster 2 memiliki karakteristik Persentase Rumah Tangga Miskin Penerima Raskin, Persentase Penduduk Miskin, dan Persentase Pengeluaran Perkapita untuk Makanan dengan Status Miskin tinggi.
\end{abstract}

Kata kunci: Clustering; Jawa Timur; K-medoids; kemiskinan

\section{K-Medoids Clustering Analysis Based on Poverty Indicators in East Java in 2020}

\begin{abstract}
The existence of the pandemic COVID-19 in Indonesia has resulted in higher poverty in Indonesia, especially in East Java, which is one of the other provinces with high cases in Indonesia. The purpose of this study is to find out the grouping of regencies/cities in East Java that have similar characteristics based on the poverty indicators in 2020. This study uses data obtained from the Badan Pusat Statistik. The method used is k-medoids clustering method which is a clustering partition method for grouping $n$ objects into $k$ clusters. Based on the results of the study, it was found that the grouping of the characteristics of each cluster formed based on the value of the poverty indicator in East Java in 2020 was 2 clusters. Where 30 regencies/cities in cluster 1 and and 8 regencies/cities in cluster 2 . Cluster 1 has the characteristics of the percentage of households that have proper sanitation, life expectancy, and a high percentage of literacy rates aged 15-55 years. While cluster 2 has the characteristics of the percentage of poor households receiving Raskin, the percentage of poor people, and the percentage of per capita expenditure on food with high poor status.
\end{abstract}

Keywords: Clustering; East Java; K-Medoids; poverty

(Article History：Received 26-09-2021; Accepted 29-11-2021; Published 05-12-2021)

\section{PENDAHULUAN}

Salah satu permasalahan yang hampir dialami oleh semua negara adalah kemiskinan. Secara umum, kemiskinan ialah suatu keadaan seseorang atau kelompok orang yang tidak dapat mencukupi kebutuhan dasarnya (Hendayanti \& Nurhidayati, 2021).
Kemiskinan yang terus meningkat menjadi permasalahan negara Indonesia yang masih belum terselesaikan sampai saat ini (Wulandary, 2015). Berbagai bentuk program dan bantuan dari pemerintah telah dilakukan untuk mengentas kemiskinan. Namun hal itu masih belum dapat menyelesaikan permasalahan kemiskinan di Indonesia. 
Pada Maret 2020, Indonesia dikejutkan dengan wabah COVID-19 yang menyebabkan tingkat kemiskinan di Indonesia terutama Jawa Timur mengalami peningkatan. Kemiskinan di Jawa Timur meningkat sebesar 4,58 juta dibanding dengan sebelum adanya pandemi (Wijayanto, 2021). Dengan adanya pandemi tersebut, pemerintah melakukan upaya penanggulangan, salah satunya adalah pembatasan aktivitas masyarakat yang hampir berdampak pada semua sektor. Salah satu pengaruh dari pembatasan kegiatan masyarakat yaitu pada sektor bisnis yang kemudian berdampak pada perekonomian. Dengan adanya pengelompokkan wilayah, dapat mengetahui masalah kemiskinan disetiap kabupaten/kota di Jawa Timur. Sehingga dapat mempermudah pemerintah dalam menjalankan kebijakan yang akan ditargetkan disetiap kabupaten/kota di Jawa Timur.

$K$-Medoids adalah metode partisi dari clustering yang menggabungkan $n$ objek ke dalam $k$ cluster. Medoids dari setiap cluster menjadi objek dari algoritma $k$-medoids. Setiap objek yang berdekatan dengan pusat cluster akan digabungkan untuk membangun cluster baru (Aurora et al., 2016). Algoritma $K$-Medoids digunakan untuk menangani kekurangan dari algoritma k-means atas kesensitifannya terhadap outlier. Keberadaan outlier pada k-means dapat mendistorsi nilai rata-rata cluster karena objek tersebut memiliki karakteristik sangat jauh terhadap sebagian besar data lainnya (Wira et al., 2019). Dengan analisis ini peneliti dapat mengetahui pengelompokkan kabupaten/kota yang memiliki karakteristik sama berdasarkan indikator kemiskinan.

Berdasarkan permasalahan kemiskinan di Indonesia, telah dilakukan penelitian dari beberapa peneliti terdahulu diantaranya yaitu penelitian dari (Wahyudi et al., 2019) yang bertujuan untuk melihat tinggi rendahnya tingkat kemiskinan di Indonesia dan diperoleh tingkat kemiskinan tertinggi di Indonesia beranggotakan 23 provinsi dan tingkat kemiskinan terendah beranggotakan 11 provinsi. Dari uraian di atas, membuat peneliti tertarik untuk mengelompokan wilayah di Jawa Timur yang memiliki karakterisitik sama berdasarkan indikatorindikator kemiskinan menggunakan metode K-Medoids Clustering, sehingga dapat dengan mudah menemukan solusi atau mengambil kebijakan untuk mengurangi tingkat kemiskinan di Jawa Timur. Terdapat perbedaan antara penelitian ini dengan kajian pustaka tersebut, diantaranya yaitu penelitian ini melakukan uji asumsi terlebih dahulu dan menggunakan visualisasi peta yang bertujuan untuk mempermudah memahami informasi clustering.

Tujuan penelitian ini yaitu untuk mengetahui pengelompokan Kabupaten/Kota di Jawa Timur yang mempunyai kesamaan karakteristik berdasarkan indikator kemiskinan Tahun 2020.

\section{METODE PENELITIAN}

Penelitian ini menggunakan data indikator kemiskinan Provinsi Jawa Timur tahun 2020 yang didapatkan dari Badan Pusat Statistik (BPS). Indikator kemiskinan yang digunakan ada 6 indikator yaitu yaitu Persentase Penduduk Miskin, Persentase Angka Melek Huruf Umur 15-55 Th, Persentase Pengeluaran Perkapita untuk Makanan dengan Status Miskin, Persentase Rumah Tangga Penerima Raskin (Beras Miskin), Angka Harapan Hidup/AHH, dan Persentase Rumah Tangga yang Mempunyai Sanitasi Layak (Febianto \& Palasara, 2019). Metode yang digunakan ialah metode $K$ Medoids Clustering Analysis. Gambar 1 merupakan diagram alir proses penelitian.

\section{Metode K-Medoids Clustering}

K-Medoids Clustering merupakan variasi metode $K$-Means. Perbedaan metode ini dibandingkan dengan $k$-means yaitu pada penggunaan medoids bukan berdasarkan ratarata setiap objek cluster (Farissa et al., 2021). $K$-Medoids digunakan untuk mengurangi sensitivitas partisi terhadap nilai outlier dalam kumpulan data (Vercillis, 2009). Tujuan dari $K$-Medoids Clustering yaitu menanggulangi kekurangan K-Means Clustering dari kesensitifannya terhadap data pencilan (outlier) yang dapat berpengaruh pada distribusi data (Han \& Kamber, 2017).

K-Medoids Clustering adalah metode partisi dari clustering yang menggabungkan $n$ objek ke dalam $k$ cluster. Objek pada sekelompok objek yang mewakili suatu cluster disebut dengan medoids (Setyawati, 2017). 


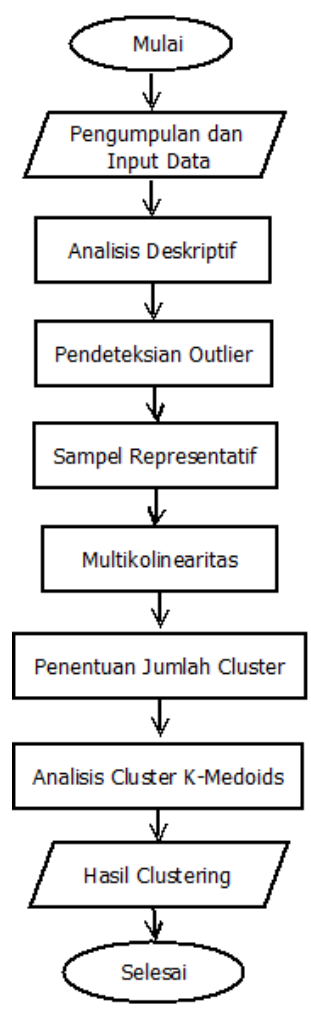

Gambar 1. Flowchart penelitian

Tahapan-tahapan menggunakan algoritma K-Medoids sebagai berikut (Wira $e t$ al., 2019):

1. Menentukan jumlah cluster sebanyak $k$ dengan pertimbangan teoritis dan konseptual.

2. Mencari jarak tiap objek terhadap cluster terdekat dengan menggunakan ukuran Euclidian distance.

$$
d_{a b}=\sqrt{\sum_{k=1}^{p}\left(x_{a k}-x_{b k}\right)^{2}}
$$

dengan:

$p \quad$ : Banyaknya variabel

$d_{a b}$ : Jarak antara objek a serta objek b

$x_{a k} \quad$ : Nilai objek a dari variabel k

$x_{b k} \quad$ : Nilai objek b dari variabel k

3. Kemudian menentukan pusat cluster baru secara random untuk dijadikan calon non medoids pada masing-masing objek.

4. Menghitung jarak antara setiap objek pada tiap-tiap cluster terhadap calon non medoids.

5. Menghitung antara jumlah simpangan (S) dengan jumlah jarak baru - jumlah jarak lama. Apabila $\mathrm{S}<0$, maka mengganti objek dengan data cluster non medoids agar terbentuk kumpulan $k$ objek baru yang disebut medoids.
6. Selanjutnya, mengulangi cara $3-5$ hingga medoids tidak berubah. Kemudian diperoleh cluster dan masing-masing anggota clusternya.

\section{HASIL DAN PEMBAHASAN}

\section{Analisis Deskriptif}

Analisis deskriptif diperlukan untuk melihat gambaran/rangkuman umum dari data yang didapatkan dengan melihat nilai minimum ( $\mathrm{min}$ ), nilai rata-rata (mean), dan nilai maksimal (max).

Tabel 1. Deskriptif indikator kemiskinan

\begin{tabular}{|c|c|c|c|c|}
\hline \multicolumn{2}{|c|}{$\begin{array}{c}\text { Indikator } \\
\text { Kemiskinan }\end{array}$} & Min & Mean & $\operatorname{Max}$ \\
\hline$X_{1}$ & $\begin{array}{l}\text { Persentase } \\
\text { Penduduk } \\
\text { Miskin }(\%)\end{array}$ & 3,890 & 11,021 & 22,780 \\
\hline$X_{2}$ & $\begin{array}{l}\text { Persentase } \\
\text { Angka } \\
\text { Melek } \\
\text { Huruf Umur } \\
15-55 \text { Th } \\
(\%)\end{array}$ & 85,56 & 96,11 & 100 \\
\hline$X_{3}$ & $\begin{array}{l}\text { Persentase } \\
\text { Pengeluaran } \\
\text { Perkapita } \\
\text { untuk } \\
\text { Makanan } \\
\text { dengan } \\
\text { Status } \\
\text { Miskin (\%) }\end{array}$ & 57,77 & 65,97 & 72,84 \\
\hline$X_{4}$ & $\begin{array}{l}\text { Persentase } \\
\text { Rumah } \\
\text { Tangga } \\
\text { Penerima } \\
\text { Raskin }(\%)\end{array}$ & 9,14 & 35,57 & 59,53 \\
\hline$X_{5}$ & $\begin{array}{l}\text { Angka } \\
\text { Harapan } \\
\text { Hidup/AHH } \\
(\%)\end{array}$ & 66,74 & 71,64 & 74,18 \\
\hline$X_{6}$ & $\begin{array}{l}\text { Persentase } \\
\text { Rumah } \\
\text { Tangga } \\
\text { yang } \\
\text { Mempunyai } \\
\text { Sanitasi } \\
\text { Layak }(\%)\end{array}$ & 44,07 & 82,07 & 98,71 \\
\hline
\end{tabular}

Berdasarkan Tabel 1 didapatkan bahwa Persentase Angka Melek Huruf Umur 15-55 Th tinggi yaitu dengan nilai minimum sebesar $85,56 \%$, nilai rata-rata sebesar $96,11 \%$, dan nilai maksimum sebesar $100 \%$. Kabupaten/ kota memiliki tingkat kemiskinan rendah apabila angka Persentase Penduduk Miskin, Persentase Rumah Tangga Miskin Penerima 
Raskin, dan Persentase Pengeluaran Perkapita untuk Makanan dengan Status Miskin rendah. Sedangkan angka Persentase Angka Melek Huruf Umur 15-55 Th, AHH, dan Persentase Rumah Tangga yang Mempunyai Sanitasi Layak tinggi.

\section{Pengecekan Outlier}

Mendeteksi outlier menggunakan boxplot untuk mengetahui apakah data yang digunakan terdapat data outlier. Jika terdapat data atau titik yang keluar dari boxplot maka data tersebut memiliki data outlier (Gambar 2).

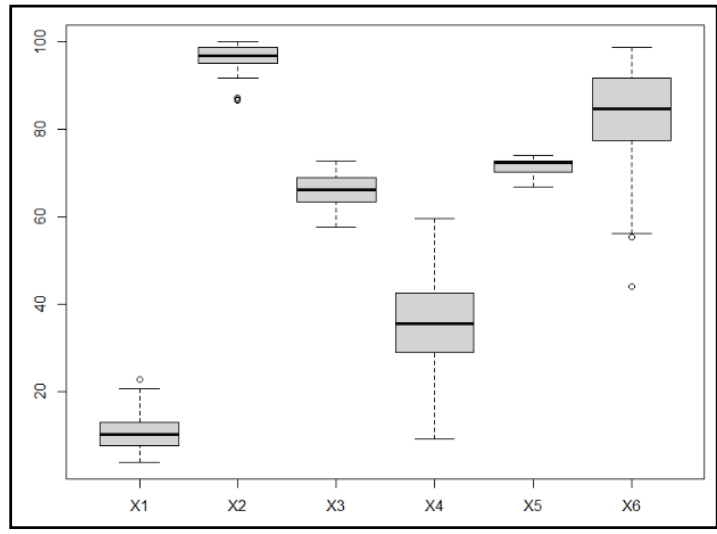

Gambar 2. Output pengecekan outlier

Berdasarkan Gambar 2 terdapat titik yang keluar dari boxplot yaitu pada variabel $X_{1}, X_{2}$, dan $X_{6}$ yang menunjukkan bahwa data yang digunakan tersebut mengandung outlier. Sehingga metode cluster yang cocok digunakan pada analisis ini yaitu metode $K$ Medoids Clustering. Pada K-Medoids yang menjadi pusat cluster yakni objek representatif (medoids) yang kemudian menempatkan setiap objek terhadap cluster terdekat dengan medoids, sehingga cocok dalam data yang mengandung outlier.

\section{Asumsi Cluster}

Pada penelitian ini terdapat asumsi yang harus dipenuhi yaitu sample representative dan tidak terdapat multikolinearitas.

\section{Sample Representative}

Berdasarkan hasil dari pengujian KMO (Kaiser Mayer Olkin) diperoleh nilai KMO sebesar 0,8046603. Nilai KMO yang diperoleh bernilai antara 0,5-1, sehingga sampel mewakili populasi atau sampel representatif yang artinya uji asumsi untuk sampel representatif terpenuhi (Ningrat et al., 2016).

\section{Uji Multikolinearitas}

Pengujian multikolinearitas memperhatikan nilai VIF, jika nilai VIF yang diperoleh $\leq 10$, maka tidak terjadi multikolinearitas (asumsi terpenuhi) (Mahmudan, 2020). Berikut merupakan uji hipotesis dari uji multikolinearitas:

Hipotesis

$\mathrm{H}_{0}$ : Tidak ada multikolinearitas

$\mathrm{H}_{1}$ : Ada multikolinearitas

Tingkat Signifikansi, $\alpha=5 \%$

Tabel 2. Output uji multikolinearitas

\begin{tabular}{cc}
\hline Indikator & VIF \\
\hline$X_{1}$ & 1,941098 \\
\hline$X_{2}$ & 2,82901 \\
\hline$X_{3}$ & 1,867921 \\
\hline$X_{4}$ & 1,508485 \\
\hline$X_{5}$ & 3,653026 \\
\hline$X_{6}$ & 3,014712 \\
\hline
\end{tabular}

Berdasarkan Tabel 2 diperoleh semua variabel memiliki nilai VIF $<10$, maka disimpulkan gagal tolak $\mathrm{H}_{0}$ (tidak ada multikolinieritas). Pada tingkat kepercayaan $95 \%$, data menunjukkan gagal tolak $\mathrm{H}_{0}$ yang artinya semua indikator kemiskinan di Jawa Timur tahun 2020 berdasarkan Kabupaten/Kota tidak terdapat korelasi antar semua variabelnya.

\section{Penentuan Jumlah Cluster}

Dalam menentukan jumlah cluster atau $k$ menggunakan metode silhouette, metode silhouette digunakan pendekatan nilai rata-rata guna memprediksi kualitas cluster yang terbentuk terbentuk (Anggara, et al., 2016). Sehingga nilai rata-rata yang semakin tinggi akan semakin baik.

Jumlah s(i) diperoleh dengan menggabungkan a(i) dan b(i) (Dewi \& Pramita, 2019):

$$
S(i)=\left\{\begin{array}{cl}
1-\frac{a(i)}{b(i)} & \text { if } a(i)<b(i) \\
0 & \text { if } a=b(i) \\
\frac{b(i)}{a(i)}-1 & \text { if } a>b(i)
\end{array}\right.
$$

Sehingga dapat dirumuskan:

$$
s(i)=\frac{b(i)-a(i)}{\max (a(i), v(i))}
$$

Berdasarkan Gambar 3, diperoleh banyaknya cluster optimum yaitu sebanyak 2 
atau $k=2$, Hal ini dilihat dari garis putusputus pada tampilan grafik metode silhouette.

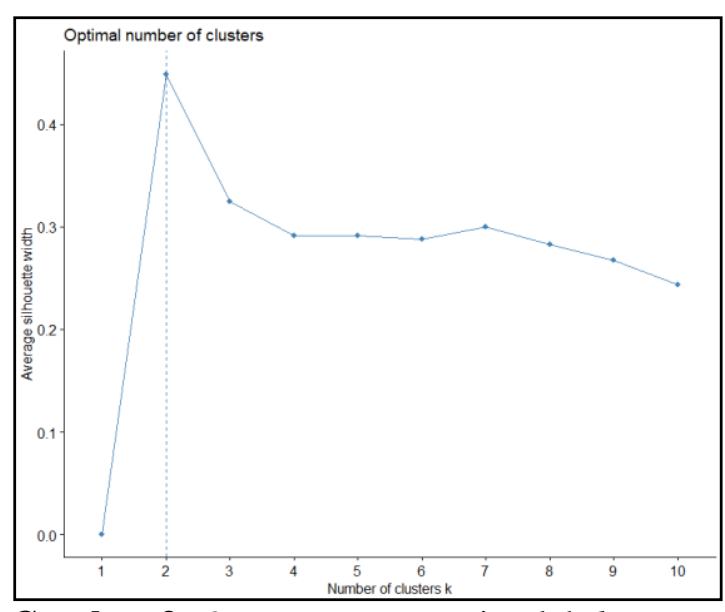

Gambar 3. Output penentuan jumlah $k$ metode silhouette

\section{Clustering}

Hasil clustering menggunakan jarak Euclidean Distance dengan cluster yang terbentuk sebanyak 2 cluster dan jumlah data yang digunakan sebanyak 38. Ada 30 kabupaten/kota pada cluster 1 serta 8 kabupaten/kota pada cluster 2 seperti pada Tabel 3.

Tabel 3. Hasil clustering

\begin{tabular}{cll}
\hline Cluster & \multicolumn{1}{c}{ Kabupaten/Kota } & Jumlah \\
\hline & Pacitan, Ponorogo, \\
& Trenggalek, Tulungagung, \\
& Blitar, Kediri, Malang, \\
& Lumajang, Banyuwangi, \\
& Pasuruan, Sidoarjo, \\
& Mojokerto, Jombang, \\
& Nganjuk, Madiun, Magetan, \\
& Kota Surabaya, Ngawi, Kota \\
& Pasuruan, Bojonegoro, \\
& Tuban, Kota Madiun, \\
& Lamongan, Kota \\
& Probolinggo, Gresik, Kota \\
& Kediri, Kota Malang, Kota \\
& Blitar, Kota Mojokerto, dan \\
& Kota Batu \\
\hline & Jember, Bondowoso, \\
& Situbondo, Probolinggo, \\
& Bangkalan, Sampang, \\
& Sumenep, dan Pamekasan \\
\hline
\end{tabular}

Dari output Gambar 4 didapatkan hasil clustering menggunakan cluster plot, diketahui bahwa cluster 1 area warna merah dan cluster 2 area warna hijau, setiap warna memiliki karakteristik yang berbeda-beda.

Kemudian, untuk melihat karakteristik dari setiap cluster dengan melihat nilai rata- rata dari masing-masing indikator disetiap clusternya.

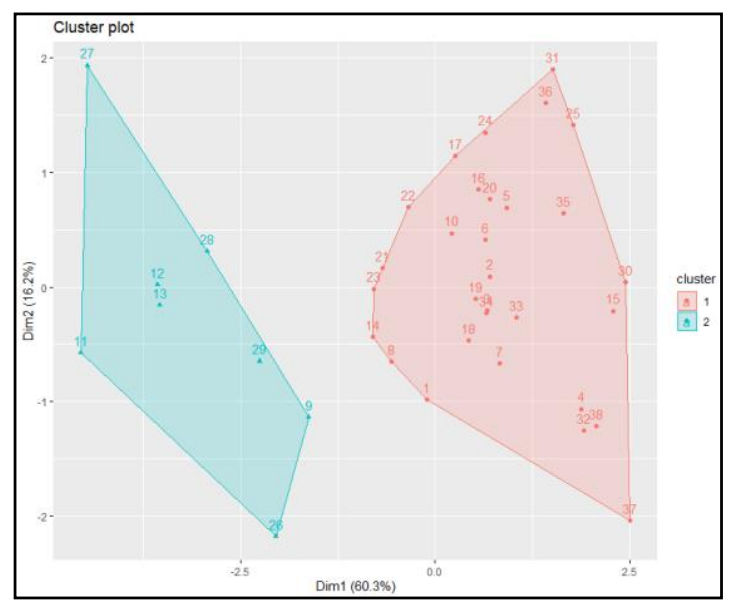

Gambar 4. Output k-medoids clustering

Tabel 4. Profilisasi data

\begin{tabular}{ccc}
\hline Indikator & Cluster $\mathbf{1}$ & Cluster 2 \\
\hline$X_{1}$ & 9,52 & 16,7 \\
\hline$X_{2}$ & 97,4 & 91,2 \\
\hline$X_{3}$ & 64,8 & 70,4 \\
\hline$X_{4}$ & 34,2 & 40,6 \\
\hline$X_{5}$ & 72,4 & 68,7 \\
\hline$X_{6}$ & 87,4 & 62 \\
\hline
\end{tabular}

Berdasarkan Tabel 4 karakteristik setiap indikator kemiskinan, didapatkan hasil clustering yang diinterpretasikan sebagai berikut:

Tabel 5. Tabel indikator

\begin{tabular}{ccc}
\hline Cluster & $\begin{array}{c}\text { Indikator } \\
\text { Tinggi }\end{array}$ & $\begin{array}{c}\text { Indikator } \\
\text { Rendah }\end{array}$ \\
\hline Cluster 1 & $X_{2}, X_{5}, X_{6}$ & $X_{1}, X_{3}, X_{4}$ \\
\hline Cluster 2 & $X_{1}, X_{3}, X_{4}$ & $X_{2}, X_{5}, X_{6}$ \\
\hline
\end{tabular}

\section{Visualisasi K-Medoids Clustering}

Visualisasi ini untuk mempermudah melihat hasil clustering berupa sebuah peta Provinsi Jawa Timur.

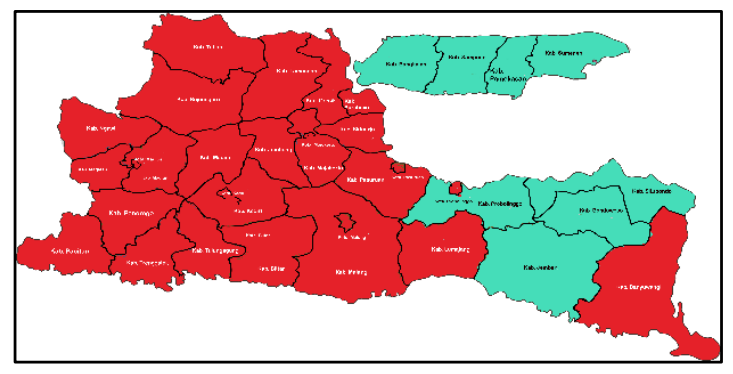

Gambar 5. Visualisasi clustering 
Berdasarkan Gambar 5 diketahui bahwa wilayah berwarna merah menunjukkan karakteristik Persentase Angka Melek Huruf Umur 15-55 Th, AHH, dan Persentase Rumah Tangga yang Mempunyai Sanitasi Layak tinggi yang terdiri dari 30 kabupaten/kota. Sedangkan wilayah berwarna hijau menunjukkan karakteristik Persentase Penduduk Miskin, Persentase Rumah Tangga Miskin Penerima Raskin, dan Persentase Pengeluaran Perkapita untuk Makanan dengan Status Miskin tinggi yang terdiri dari 8 kabupaten/kota.

\section{KESIMPULAN}

Dengan menggunakan analisis $k$ medoids clustering diperoleh cluster optimal sebanyak 2 cluster. Terdapat 30 kabupaten/kota pada cluster 1 dan 8 kabupaten/kota pada cluster 2. Cluster 1 memiliki karakteristik Persentase Rumah Tangga yang Mempunyai Sanitasi Layak, AHH, dan Persentase Angka Melek Huruf Umur 15-55 Th tinggi. Sedangkan cluster 2 memiliki karakteristik Persentase Rumah Tangga Miskin Penerima Raskin, Persentase Penduduk Miskin, Persentase Pengeluaran Perkapita untuk Makanan dengan Status Miskin tinggi.

\section{DAFTAR PUSTAKA}

Anggara, M., Sujiani, H. \& Nasution, H. 2016. Pemilihan Distance Measure Pada KMeans Clustering Untuk Pengelompokkan Member Di Alvaro Fitness. Jurnal Sistem dan Teknologi Informasi (JUSTIN), 1(1): 1-6.

Aurora, P., Deepali \& Varshney, S., 2016. Analysis of K-means an K-Medoids Algorithm for Big Data. Procedia Computer Science, 78: 507-512.

Dewi, D.A.I.C. \& Pramita, D.A.K. 2019. Analisis Perbandingan Metode Elbow Dan Sillhouette Pada Algoritma Clustering K-Medoids Dalam Pengelompokkan Produksi Kerajinan Bali. Jurnal Matrix, 9(3): 102-109.
Farissa, R.A., Mayasari, R. \& Umaidah, Y. 2021. Perbandingan Algoritma KMeans dan K-Medoids Untuk Pengelompokkan Data Obat dengan Silhouette Coefficient. Journal of Applied Informatics and Computing (JAIC), 5(2): 109-116.

Febianto, N.I. \& Palasara, D.N. 2019. Analisis Clustering K-Means Pada Data Informasi Kemiskinan di Jawa barat Tahun 2018. SISFOKOM, 8(2): 130139.

Han, J. \& Kamber, M. 2017. Data Mining, Concept and Techniques. Morgan Kauffman Publisher, Waltham.

Hendayanti, N.P.N. \& Nurhidayati, M. 2021. Klasifikasi Tingkat Keparahan Kemiskinan Provinsi di Indonesia. Jurnal Matematika dan Pendidikan Matematika, 5(1): 14-21.

Mahmudan, A. 2020. Clustering of District or City in Central Java Based COVID-19 Case Using K-Means Clustering. Jurnal Matematika, Statistika, \& Komputasi (JMSK), 17(1): 1-13.

Ningrat, D.R., Maruddani, D.A.I. \& Wuryandari, T. 2016. Analisis Cluster dengan Algoritma K-Means dan Fuzzy C-Means Clustering untuk Pengelompokan Data Obligasi Korporasi. Jurnal Gaussian, 5(4): 641650.

Setyawati, A.W. 2017. Implementasi Algoritma Partitioning Around Medoid (PAM) untuk Pengelompokkan Sekolah Menengah Atas di DIY Berdasarkan Nilai Daya Serap Ujian Nasional [Skripsi]. Fakultas Sains dan Teknologi, Universitas Sanata Darma, Yogyakarta.

Vercillis, C. 2009. Business Intelligence, Data Mining and Optimization for Desicion Making. Wiley, Milan.

Wahyudi, D., Handrizal, H \& Wanto, A. 2019. Mengelompokkan Garis Kemiskinan Menurut Provinsi Menggunakan Algoritma K-Medoids. Prosiding Seminar Nasional Riset Informasi Sains (SENARIS): 452-461. 
Wijayanto. 2021. Dampak Pandemi Covid19, Penduduk Miskin di Jatim Meningkat. [Online] Availabl at: https://radarsurabaya. jawapos.com /read/2021/03/30/250918/dampakpandemi-covid-19-penduduk-miskindi-jatim-meningkat

Wira, B., Budianto, A.E. \& Wiguna, A.S. 2019. Implementasi Metode KMedoids Clustering Mengetahui Pola Pemilihan Program Studi Mahasiswa Baru Tahun 2018 di Universitas Kanjuruhan Malang. Jurnal Terapan Sains \& Teknologi, 1(3): 54-69.
Wulandary, F.H. 2015. Pengaruh Pertumbuhan Ekonomi Inflasi, Pengangguran, dan Pendidikan Terhadap Kemiskinan Provinsi di Indonesia Tahun 2008-2012 [Skripsi]. Universitas Atma Jaya, Yogyakarta. 